\title{
A CLINICAL STUDY ON MANIFESTATIONS AND MANAGEMENT OF CHOLESTEATOMA EAR
}

\author{
B. Radhika1, Santosh Kumar Misra ${ }^{2}$
}

${ }^{1}$ Senior Resident, Department of Otorhinolaryngology, MKCG Medical College, Berhampur, Odisha.

2Professor and HOD, Department of Otorhinolaryngology, MKCG Medical College, Berhampur, Odisha.

\begin{tabular}{l}
\hline ABSTRACT \\
BACKGROUND \\
Cholesteatoma is a sac in the middle ear cleft lined by stratified squamous epithelium and containing keratin debris. It is capable of \\
soft tissue and bone destruction, thus leading to several, even life-threatening, complications. Surgical therapy is the mainstay of \\
management. \\
Aims and Objectives- To study the distribution of cholesteatoma in different age groups \& various socioeconomic classes, its \\
various modes of presentation, complications, different modes of management and postoperative outcome.
\end{tabular}

\section{MATERIALS AND METHODS}

The study has been carried out on 80 patients in the Department of Otorhinolaryngology, MKCG Medical College \& Hospital, Berhampur, Odisha, from October 2011 to September 2013. Thorough history of all the patients was taken and complete ear, nose and throat examination was done. Hearing was assessed by pure tone audiometry. HRCT scan of bilateral temporal bones was done in patients with complications. All the patients underwent canal wall down mastoidectomy along with postoperative follow-up. Setting and Design- Prospective study conducted at a tertiary referral institution.

\section{RESULTS}

Cholesteatoma was most common in the second decade of life, mostly in low socioeconomic class. The common mode of presentation was fowl smelling ear discharge followed by conductive hearing loss. 30 cases presented with complications-21 cases of mastoid abscess, 3 cases of meningitis, 1 case each of facial nerve paralysis, Luc's abscess, zygomatic abscess, jugular vein thrombosis, petrositis and temporal lobe abscess. All cases were treated with Canal wall down mastoidectomy, with tympanoplasty done in 11 cases. Postoperative complications like discharging cavity was present in 18 cases. Hearing improvement was more than $10 \mathrm{~dB}$ in $70 \%$ cases.

\section{CONCLUSION}

Cholesteatoma is an aggressive disease. Improving socioeconomic condition and increasing awareness about the disease will prevent the progression of the disease \& its complications can be reduced. Thus, basic knowledge about the disease among the medical practitioners promotes timely diagnosis and prompt referral, so that appropriate surgical intervention would reduce mortality and morbidity due to cholesteatoma.

\section{KEYWORDS}

Cholesteatoma, Canal wall down mastoidectomy, Modified Radical Mastoidectomy, Radical Mastoidectomy, Tympanoplasty, TORP.

HOW TO CITE THIS ARTICLE: Radhika B, Misra SK. A clinical study on manifestations and management of cholesteatoma ear. J. Evolution Med. Dent. Sci. 2017;6(1):19-22, DOI: 10.14260/Jemds/2017/6

\section{BACKGROUND}

Cholesteatoma is a sac in the middle ear cleft lined by stratified squamous epithelium and containing keratin debris. Cholesteatoma can be divided into two types $(1,2)-$

1. Congenital 2 . Acquired- primary \& secondary

Congenital cholesteatomas are thought to arise from embryonal rests of epithelial cells present behind an intact tympanic membrane. Acquired cholesteatoma is seen in association with chronic suppurative otitis media. Primary acquired cholesteatoma arise in the clinical setting of accumulation of squamous debris in a pre-existing retraction

Financial or Other, Competing Interest: None.

Submission 28-11-2016, Peer Review 21-12-2016,

Acceptance 28-12-2016, Published 02-01-2017.

Corresponding Author:

Dr. B. Radhika,

Department of Otorhinolaryngology,

MKCG Medical College,

Berhampur-760004,

Odisha.

E-mail: dr.radhika.b@gmail.com

DOI: $10.14260 /$ jemds $/ 2017 / 6$ pocket. Secondary acquired cholesteatoma is most often accompanied by a perforation of the tympanic membrane with subsequent migration of squamous epithelium into the middle ear.

Cholesteatoma may remain clinically silent for a significant period of time until the disease has become quite extensive. Although cholesteatoma is considered to be a benign process, it is capable of soft tissue and bone destruction, thus leading to several, sometimes, even lifethreatening extracranial as well as intracranial complications. $(1,3)$ Hearing loss and otorrhoea are common manifestations. However with the presence of complications, the patient will develop earache, fever, chill and rigor, postauricular swelling, vomiting, vertigo, headache, post auricular discharging sinus, facial weakness etc. $(4,5)$

Diagnosis is done by clinical examination, and CT/ MR imaging is indispensable for preoperative assessment.(6) Surgical therapy is the mainstay of management(7), followed by prolonged, diligent postoperative check-up due to the significant rate of recidivistic disease. The primary objective is eradication of all diseased tissue with establishment of dry safe ear. Maintenance or restoration of hearing is a secondary 
goal. A favourable outcome depends to a large degree on an early diagnosis, but diagnosis is delayed in most instances. Thus, complications are frequent. $(1,8)$

This study was conducted to analyse the distribution of cholesteatoma in different age groups \& various socioeconomic classes, its various modes of presentation, complications, different modes of management and postoperative outcome, so that it would promote timely diagnosis and prompt referral, and appropriate surgical intervention would reduce mortality and morbidity due to cholesteatoma.

\section{MATERIALS AND METHODS}

The present study consists of 80 patients having definitive cholesteatoma, with or without complications, in the Department of Otorhinolaryngology, MKCG Medical College \& Hospital, Berhampur, Odisha, from October 2011 to September 2013. All the patients were clinically assessed. In all the cases, thorough history was taken including presenting complaints, duration and symptoms; complete ear, nose and throat examination was done. Hearing was assessed by pure tone audiometry. X-ray of bilateral mastoids in Law's lateral view was done in all patients and HRCT scan of bilateral temporal bones was done in patients with complications. They were reviewed for the following criteria: age, sex, clinical presentation, socioeconomic status, the cholesteatoma site, type of ear discharge, the contra lateral ear, type and degree of hearing loss and complications. Routine pre-operative investigations were done. All the patients underwent surgery under general anaesthesia by postaural approach. Postoperative follow-up was on 7 th day, after 6 weeks and after 6 months- patients were looked for any ear discharge, healing of the mastoid cavity, any debris/recurrent/residual disease or any other postoperative complications.

\section{Inclusion Criteria}

All patients with cholesteatoma who had undergone surgery.

\section{Exclusion Criteria}

Patients with recurrent /residual cholesteatoma and reluctant patients.

\section{RESULTS}

In this study cholesteatoma was found most commonly in the age group of 11-20 years. The lowest and highest age of the patients at presentation was 04 years and 60 years respectively with a mean age of 19 years. The disease found to be more common in adults ( $>15$ years) $(63.75 \%)$ as compared to children $(36.25 \%)$. There were 43 male $(53.75 \%)$ and 37 female (46.25\%) subjects with male: female ratio of 1:1.6. Our study revealed that cholesteatoma was most common in low socioeconomic class (70\%). Poor hygiene, malnutrition and overcrowding are the main reasons for high prevalence of cholesteatoma in these people. The most common mode of presentation was purulent ear discharge (100\%) followed by hearing loss (85\%). As per the character of discharge, all the ears with cholesteatoma had malodorous discharge (100\%) of which $92.50 \%$ had scanty, $7.5 \%$ had profuse discharge, $36.25 \%$ had blood stained discharge. Other clinical features include- mass in ear (granulation/polyp) in 29 cases (36.25\%), post aural abscess in 21 cases (26.25\%), 2 cases (2.5\%) had vertigo and 1 patient $(1.25 \%)$ had facial nerve palsy. We found the incidence of cholesteatoma in posterosuperior quadrant $(57.5 \%)$ to be more common than attic cholesteatoma (42. $5 \%)$.Bilateral ear disease found in 9 patients $(11.25 \%)$ and in 7 cases $(8.75 \%)$ it was of unsafe type.

Most common type of hearing loss was conductive hearing loss (88.5\%), as revealed by tuning fork tests \& pure tone audiometry. Sensorineural hearing loss seen in 2 cases $(2.5 \%)$ while 7 patients had mixed hearing loss (9\%). Most of the cases $(44.9 \%)$ had moderate hearing loss. 21 patients $(26.9 \%)$ had mild hearing impairment. Profound hearing loss reported in 1 patient. This patient had mixed hearing loss.

\begin{tabular}{|c|c|c|c|}
\hline Complications & $\begin{array}{c}\text { Postero- } \\
\text { superior } \\
\text { Quadrant } \\
\text { Cholesteatoma }\end{array}$ & $\begin{array}{c}\text { Attic } \\
\text { Cholesteatoma }\end{array}$ & Total \\
\hline $\begin{array}{c}\text { Postaural } \\
\text { Abscess/Fistula }\end{array}$ & $\begin{array}{c}14 \\
(17.5 \%) \\
\end{array}$ & $\begin{array}{c}7 \\
(8.75 \%) \\
\end{array}$ & $\begin{array}{c}21 \\
(26.25 \%) \\
\end{array}$ \\
\hline Meningitis & $\begin{array}{c}3 \\
(3.75 \%)\end{array}$ & - & $\begin{array}{c}3 \\
(3.75 \%) \\
\end{array}$ \\
\hline Facial Nerve Palsy & - & $\begin{array}{c}1 \\
(1.25 \%)\end{array}$ & $\begin{array}{c}1 \\
(1.25 \%)\end{array}$ \\
\hline Luc's Abscess & - & $\begin{array}{c}1 \\
(1.25 \%) \\
\end{array}$ & $\begin{array}{c}1 \\
(1.25 \%) \\
\end{array}$ \\
\hline Zygomatic Abscess & $\begin{array}{c}1 \\
(1.25 \%)\end{array}$ & - & $\begin{array}{c}1 \\
(1.25 \%) \\
\end{array}$ \\
\hline $\begin{array}{l}\text { Jugular Vein } \\
\text { Thrombosis }\end{array}$ & 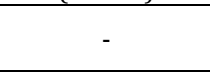 & $\begin{array}{c}1 \\
(1.25 \%) \\
\end{array}$ & $\begin{array}{c}1 \\
(1.25 \%) \\
\end{array}$ \\
\hline Petrositis & $\begin{array}{c}1 \\
(1.25 \%) \\
\end{array}$ & - & $\begin{array}{c}1 \\
(1.25 \%) \\
\end{array}$ \\
\hline $\begin{array}{c}\text { Temporal Lobe } \\
\text { Abscess }\end{array}$ & $\begin{array}{c}1 \\
(1.25 \%)\end{array}$ & - & $\begin{array}{c}1 \\
(1.25 \%)\end{array}$ \\
\hline \multicolumn{4}{|c|}{ Table 1. Complications \& site of disease $(n=30)$} \\
\hline
\end{tabular}

The most common complication seen at the time of presentation was mastoid (post auricular) abscess (26.25\%). Complications were more common in patients with cholesteatoma in the posterosuperior quadrant $(25 \%)$ as compared to those in attic area (12.5\%). 50 (62.5\%) patients had no complications. Out of 21 cases with mastoid abscess, 7 patients presented with discharging fistula. All these patients were treated with incision and drainage of abscess, intravenous antibiotics and regular dressing followed by canal wall down mastoidectomy. Patients with meningitis had fever, vomiting and neck rigidity, with positive Kernig's sign. One patient with zygomatic abscess presented with fever, headache \& facial swelling. The affected external auditory canal was swollen and erythematous. The patient was treated with modified radical mastoidectomy after draining the abscess. One patient with temporal lobe abscess presented with fever, headache, drowsiness and vertigo. He underwent radical mastoidectomy after excision of the abscess in the neurosurgery department. The patient recovered completely after the illness. The patient with facial nerve paralysis recovered completely after undergoing modified radical mastoidectomy. One patient with petrositis had features of Gradenigo's syndrome - ear discharge, diplopia (due to lateral rectus palsy) and retro-orbital pain. The patient had complete recovery with a course of intravenous antibiotics and mastoidectomy. The patient with jugular vein thrombosis presented with ear discharge, headache, pain in neck and tenderness along the jugular vein. She was treated with intravenous antibiotics and modified radical mastoidectomy. 
All the cases underwent canal wall down mastoidectomy. Out of 80 patients, 60 cases underwent modified radical mastoidectomy, 8 cases underwent radical mastoidectomy and were called for second stage surgery at a later date. Canal wall down mastoidectomy with reconstruction of the middle ear was done by type II \& type III tympanoplasty in $9 \& 2$ patients respectively. TORP (Total Ossicular Replacement Prosthesis) was used in 1 patient. Temporalis fascia graft used by underlay technique. Ossiculoplasty was done using autologous incus except in 1 patient where TORP was used. Post-operative complications noted during 6 months of follow up showed that 18 patients $(22.5 \%)$ had discharging mastoid cavity. 9 patients developed granulations in the cavity, leading to discharge. All the exuberant granulation removed and the margins were cauterised chemically with silver nitrate, to produce advancement of healing process. In all the patients, cavity got epithelised well and healing was achieved after 2 weeks of antibiotic steroid topical drops. In the rest 9 patients $(11.25 \%)$ discharge was due to cavity infection with accumulated debris. Frequent suction cleaning of mastoid cavity was done and infection controlled with oral \& topical antibiotics. 1 patient developed facial nerve paralysis in the 3rd postoperative day. Oral steroids and antibiotics were prescribed. There was complete recovery without any deformity. 2 patients who underwent radical mastoidectomy experienced giddiness in the immediate postoperative period. They were treated with anti-vertigo drugs. Vertigo subsided within few days. 1 patient had stitch abscess on 6th postoperative day. The abscess was drained \& the underlying suture was cut. None of the patients had recurrent or residual cholesteatoma in our study.

Hearing results at 6 months follow up $(n=10)$ showed that out of 12 patients of tympanoplasty, 2 had perforations in the tympanic membrane and excluded from hearing status assessment. $70 \%$ of the patients had significant improvement of air-bone gap ( $>10 \mathrm{~dB}$ gain). With TORP, the gain is $16 \mathrm{~dB}$ (pre-operative air-bone gap-32 dB; post-operative air-bone gap $-16 \mathrm{~dB})$.

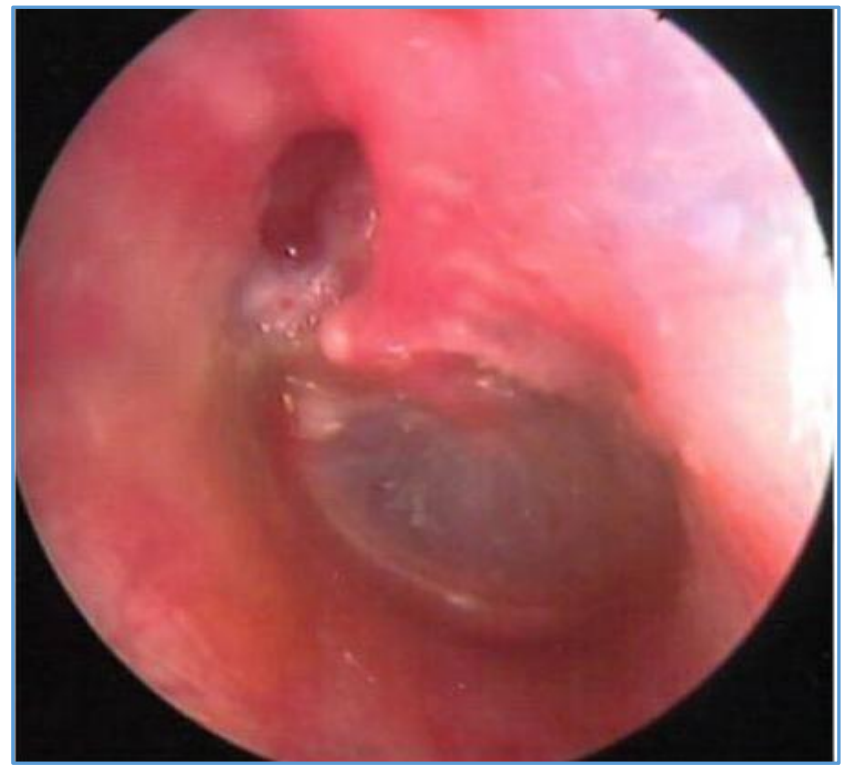

Figure 1. Attic perforation (Left ear)

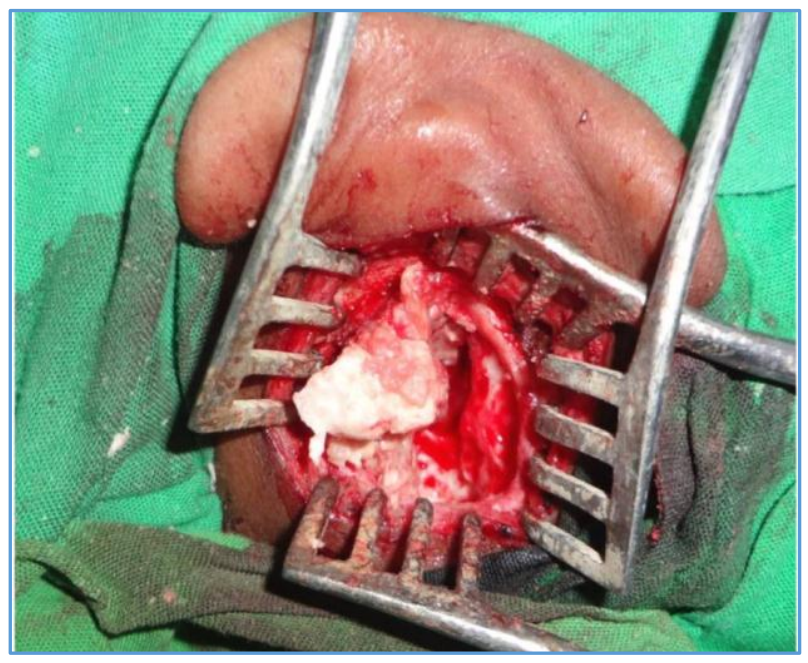

Figure 2. Cholestaetoma in mastoid cavity with sinus plate erosion

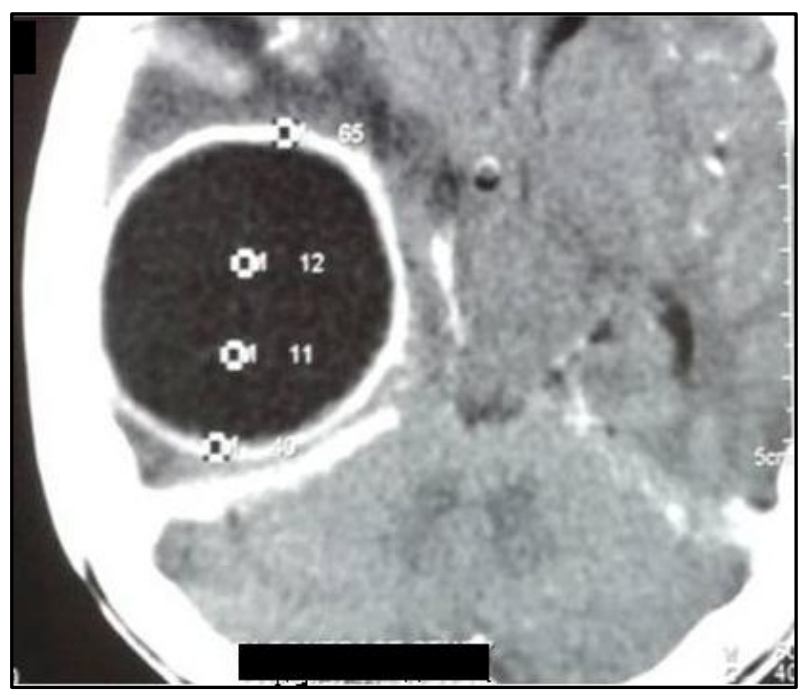

Figure 3. Otogenic right temporal lobe abscess

\section{DISCUSSION}

In this study cholesteatoma is found most commonly in the age group of 11-20 years. This finding is similar to the study by Mohammed Yousuf et al. (2011) (5) who documented that the majority of the patients were in the age group of 11-20 years with a mean age of 17.2 years. Our study found a slight male preponderance of cholesteatoma with a male: female ratio of 1:1.16. Jose Evandro et al(2011) ${ }^{(9)}$ also found that males predominated (64.7\%) compared to females (35.3\%) among both adults and children. Cholesteatoma is most common in low socioeconomic class $-70 \%$ cases of our study. Viswanatha and Kaja Naseeruddin(10) had similar findings majority of cases $(62.5 \%)$ were from the low socioeconomic group. A study by, Homoe P (2001)(11) found that children living in very crowded households had an increased risk of chronic otitis media. This may be one of the reasons why most of our patients with cholesteatoma are from poor background.

Ear discharge was found in all cases. Salman A A., Azhar H., Muhammad E K. et al. (2009) (12) also found ear discharge in $100 \%$ of the cholesteatoma cases in their study. We found the incidence of cholesteatoma in posterosuperior quadrant 
(57.5\%) to be more common than attic cholesteatoma (42.5\%). A similar incidence was demonstrated by Mohammed Yousuf et al.(2011) (5) -poster superior marginal $(69.23 \%)$ or in the attic region (30.77\%).Bilateral ear disease found in 9 patients $(11.25 \%)$ and in 7 cases $(8.75 \%)$ it is of unsafe type. According to Hassman et al(2012)(13), bilateral cholesteatoma was diagnosed in $12.9 \%$ of children.

Majority of the patients had conductive hearing loss (88.5\%), as revealed by tuning fork tests \& pure tone audiometry. Sensorineural hearing loss seen in 2 cases (2.5\%) while 7 patients had mixed hearing loss (9\%). Regarding severity of hearing loss, most of the cases (44.9\%) had moderate hearing loss, 21 patients $(26.9 \%)$ had mild hearing impairment. Profound hearing loss reported in 1 patient. This patient had mixed hearing loss. These findings are comparable to the study by Mohammed Yousuf et al (2011) (5) in which maximum patients had moderate conductive of deafness (74.47\%) followed by mild conductive deafness (19.15\%) and a few with mixed deafness (6.38\%).

30 cases presented with complications-21 cases of mastoid abscess, 3 cases of meningitis, 1 case each of facial nerve paralysis, Luc's abscess, zygomatic abscess, jugular vein thrombosis, petrositis and temporal lobe abscess. In a study by Mohammad Ajalloueyan (2006) (14) out of 148 patients, major complications caused by the disease included 1 case of brain abscess, 2 cases of facial nerve paralysis, 2 cases of labyrinthine fistula, and 4 cases of meningitis. During post-operative follow up , 62 cases $(77.5 \%)$ had dry ears while 18 cases $(22.5 \%)$ had discharge, which showed better results as compared to the study by Yaor M.A. et al (2006)(15). $62.5 \%$ of the cavities (canal wall down) in their study were dry up to 12 months post-operative follow-up and $28 \%$ were wet. Regarding hearing gain, after 6 months, $70 \%$ of the patients had significant improvement of air-bone gap $(>10 \mathrm{~dB}$ gain). With TORP, the gain is $16 \mathrm{~dB}$ (pre-operative air-bone gap-32 dB; post-operative air-bone gap -16 dB). Thus, hearing improvement is better in comparison to a study by Berenholz et al. (2000) (16) in which $64 \%$ of air-bone gaps were closed to within $20 \mathrm{~dB}$ in ossiculoplasty with canal wall down mastoidectomy. There was no recurrence in our study. This may be due to the short period of follow up. In a study by Mohammad Ajalloueyan (2006)(14), the patients were followed up for at least 10 years (range, 10-16 years; mean12.3 years) and the recurrence rate of $7 \%$ was noted.

\section{CONCLUSION}

Cholesteatoma is an aggressive disease. The bone eroding properties and its propensity to spread renders cholesteatoma to cause several extracranial and intracranial complications which can be life threatening. Moreover, the silent nature of the disease with few symptoms eludes the patient resulting in the delay in treatment, leading to complications in the long run. In our study an endeavour is made to study the clinical manifestations, complications and various modes of management of cholesteatoma. The disease is more common in children of 2 nd decade. It most commonly presents with scanty, purulent discharging ear, frequently accompanied by hearing impairment. Surgical removal of cholesteatoma is the keystone of treatment. The primary objective is eradication of all diseased tissue with establishment of dry safe ear; maintenance or restoration of hearing being the secondary goal. $70 \%$ of the patients in our study who underwent modified radical mastoidectomy with tympanoplasty had good hearing results with $>10 \mathrm{~dB}$ improvement of air-bone gap. Thus, basic knowledge about cholesteatoma among the medical practitioners promotes timely diagnosis and prompt referral, so that appropriate surgical intervention would reduce mortality and morbidity.

\section{REFERENCES}

[1] Frickmann H, Zautner AE. Cholesteatoma-a potential consequence of chronic middle ear inflammation. Otolaryngology An Open Access Journal 2012.

[2] Persaud R, Hajioff D, Trinidade A, et al. Evidence-based review of aetiopathogenic theories of congenital and acquired cholesteatoma. The Journal of Laryngology \& Otology 2007;121(11):1013-9.

[3] Hammami B, Mnejja M, Chakroun A, et al. Cholesteatoma of the frontal sinus. European Annals of Otorhinolaryngology, Head Neck Diseases 2010;127(6):213-6.

[4] Alauddin M. Complications of otitis media: a review. The Orion Medical Journal 2003;14:43-6.

[5] Yousuf M, Majumder KA, Kamal A, et al. Clinical study on chronic suppurative otitis media with cholesteatoma. Bangladesh Journal of Otorhinolaryngology 2011;17(1):42-7.

[6] Nevoux J, Lenoir M, Roger G, et al. Childhood cholesteatoma. European Annals of Oto-rhinolaryngology, Head Neck Diseases 2010;-127(4):143-50.

[7] Palva T, Ramsay H. Chronic inflammatory ear disease and cholesteatoma: creation of auxiliary attic aeration pathways by microdissection. Am J Otol 1999;20(2):145-51.

[8] Kim S, Chang P. Cholesteatoma-diagnosing the unsafe ear. Australian Family Physician 2008;37(8):631-8.

[9] Aquino JE, Cruz Filho NA, de Aquino JN. Epidemiology of middle ear and mastoid cholesteatomas: study of 1146 cases. Brazilian Journal of Otorhinolaryngology 2011;77(3):341-7.

[10] Viswanatha B, Naseeruddin K. Neurotologic complications of chronic otitis media with cholesteatoma. Journal of Neurology and Epidemiology 2013;1:20-30.

[11] Homoe P. Otitis media in Greenland. Studies on historical, epidemiological, microbiological and immunological aspects. International Journal of Circumpolar Health 2001;60(suppl 2):1-54.

[12] Salman AA, Azhar H, Muhammad EK, et al. Analytical study of ossicular chain in middle ear cholesteatoma. Annals 2009;15(3):134-7.

[13] Hassman-Poznańska E, Kurzyna A, Trzpis K, et al. The status of the contralateral ear in children with acquired cholesteatoma. Acta Otolaryngol 2012;132(4):404-8.

[14] Ajalloueyan M. Experience with surgical management of cholesteatomas. Arch Otolaryngol Head Neck Surg 2006;132(9):931-3.

[15] Yaor MA, El-Kholy A, Jafari B. Surgical management of chronic suppurative otitis media: a 3-year experience. Annals of African Medicine 2006;5(1):24-7.

[16] Berenholz LP, Rizer FM, Burkey JM, et al. Ossiculoplasty in canal wall down mastoidectomy. Otolaryngol Head Neck Surg 2000;123(1 Pt 1):30-3. 